\title{
Emotional Intelligence and Academic Performance of Undergraduates: Correlations, Implications and Interventions
}

\author{
Oyewunmi, Adebukola E. \\ adebukola.oyewunmi@covenantuniversity.edu.ng \\ Osibanjo, Adewale 0. \\ ade.osibanjo@covenantuniversity.edu.ng \\ Adeniji, Anthonia A. \\ anthonia.adenij@covenantuniversity.edu.ng
}

Department of Business Management, Covenant University, Ogun State, Nigeria

\section{Doi:10.5901/mjss.2016.v7n1p509}

\section{Abstract}

This research investigates the correlation between emotional intelligence and academic performance of undergraduates. The survey design was adopted to sample one hundred and fifty two (152) final year undergraduates of a university in South-West, Nigeria. The regression analytic tool was deployed to analyze data. The results show a correlation between emotional intelligence and academic performance; affirming that emotional intelligence predicts academic performance. The outcomes of the research suggest the need for stakeholders and policy-makers to make concerted efforts towards reappraising higher education in Nigeria, in order to meet the demands of industry and the corporate world.

Keywords: emotional intelligence, performance, workplace, higher education, curricular

\section{Introduction}

The strength of an organization depends on the quality of its people. Human resource managers are thus inclined to recruit graduates who possess excellent academic profiles, as it is usually perceived, that such persons will add value to the organization. Aside this, modern organizations are also looking for essential qualities, such as, emotional intelligence in prospective employees. Many people consider universities to be the ivory tower of learning, as well as the bedrock of human capital for developed and developing societies. Therefore, it is imperative that students are provided with a comprehensive and balanced training to ensure both high academic performance and emotional maturity. This is why The University of Yale, for instance, has instituted an Emotional Intelligence Centre with the objective of teaching emotional intelligence competencies to students (Wesley, 2013). Currently, the Nigerian university system has not attained the status of explicitly incorporating emotional intelligence in its curricular. The closest the higher education system has achieved with regards to emotional intelligence is narrowly captured in disciplines such as psychology, human resource management, philosophy, guidance and counseling.

In 2014, The Nigerian Economic Summit focused its attention on the importance of re-evaluating Nigeria's educational sector in terms of quality and value, because of its strategic role in driving transformational national development. Discussions also highlighted the importance of a national consensus on the objectives of the Nigerian educational system and the need for an agreement on the core competencies, skills, attitudes and learning outcomes of the system (Nigerian Economic Summit Group, 2014). The focus of the summit is in alignment with what obtains globally, as countries are not only investing in education, but also making structural adjustments to curricular to make it practical for the workplace and society at large. It is expected that this focus will translate into positive and concrete steps that would facilitate the emergence of a robust educational system for the next generation of students.

Students proceed to the university to acquire knowledge and skills to make them relevant in the workplace. Thus, it is paramount for universities to effectively capture these functions. In Nigeria, there is a fundamental challenge of disconnect between the university system and the corporate world. This can be attributed to the relative gap that exists in the curricular of several universities, particularly in terms of teaching core competencies such as emotional intelligence. 
The effect of this gap is the production of graduates that are not duly equipped to confront the complexities of the work environment. It can be argued that if Nigerian universities evolve and adapt appropriately, it will result in the creation of platforms that will nurture emotional competencies and in the long run enhance the pool of skills and expertise. Moreover, the expectation in such circumstances is that social exchange will be enhanced at multiple levels. Thus, this research examines the correlation between emotional intelligence and academic performance. The possibility of a significant relationship highlights the need to re-evaluate higher education in Nigeria.

\section{Literature Review}

\subsection{Conceptual Framework}

Emotional intelligence is not an entirely new management concept. Its origin can be traced to the human intuitive sense and the need for effective interpersonal skills in relationships. Goleman (1997) popularized the term and states that emotional intelligence encompasses the knowledge of:

'what you feel and being able to handle those feelings without having them swamp you, being able to motivate yourself to get jobs done, to be creative and perform at your peak and sensing what others feel and handling relationships effectively' (p.4)

According to Mayer and Salovey (1997), emotional intelligence is the capability to recognize, comprehend, and manage emotions in one's self and in others. The competencies of emotional intelligence include; the capacity to comprehend emotions in oneself, being able to manage and regulate these emotions, the ability to comprehend the emotions of other people to facilitate the effective management of relationships (Goleman, 1995; Salovey and Mayer, 1990). Essentially, the substance of emotional intelligence is entrenched in the relationship an individual has with him or herself, and the translation or manifestation of this on the management of relationships and other dynamics within the environment. Supporters of the construct have endorsed it has been a novel approach to comprehend human behaviour and performance particularly in the workplace (McEnrue and Groves, 2006). Woodruffe (2001) however criticized the construct, stating that it is an untested theory that does not explain nor aid the understanding of human behaviour.

The possibility of correlation between emotional intelligence and academic performance has created a surge of interest amongst scholars in recent years. Before the construct of emotional intelligence was established, customary measures of cognitive thinking models i.e. IQ tests, examinations, grades and test scores, were relied upon to determine academic performance and predict success in life (Dulewicz and Higgs, 2000). Goleman (1996) asserts that the intelligence quotient of an individual is only instrumental to overall success in life by about $20 \%$. Gardner and Hatch (1989) advanced the theory of multiple intelligences and concluded that there are 'other' intelligences different from IQ that play prominent roles in determining an individual's success. Goleman (1996) maintains that what Gardner and Hatch (1989) refer to as 'multiple intelligences' or 'other intelligences' is majorly emotional intelligence, and that individuals who possess an admixture of intelligence quotient and emotional intelligence have the potential to be generally successful in life. Other commentators (Steiner, 1997; Salovey and Mayer, 1990) propose that the amalgamation of intelligence quotient and emotional intelligence explicates further differences in outcomes than intelligence quotient alone. However, they state that a measure intelligence quotient is essential for the fusion with emotional intelligence to result in distinctive success in life outcomes.

\subsection{Theoretical Framework}

An important theory in the study of emotional intelligence is the theory of multiple intelligences which was proposed by Gardner (1983). The theory was originally proposed to address the existence of other intelligences that could not be categorized as cognitive intelligence. This theory is based on the perspective that individuals have various abilities and aptitudes. Hence, the concept of intelligence should not be stereotyped. According to Gardner (1983), the different types of intelligence include intrapersonal intelligence and interpersonal intelligence. Gardner and Hatch (1989) identified the trait of an interpersonally intelligent person as possessing capacities to discern and respond appropriately to the moods, temperaments, motivations, and desires of other people. The traits of an intra-personally intelligent person includes, having access to one's own feelings, the ability to discriminate amongst these feeling to guide behaviour; knowledge of one's strengths, weaknesses, desires, and intelligences. 


\subsection{Empirical Framework}

A study by Sergio (2001) found that cognitive ability and emotional intelligence are related to productivity ratings. This finding implies that both mental abilities and emotional intelligence are autonomous and vital indicators of performance. Thus, intelligence quotient and emotional intelligence are key ingredients of performance, and emotions are just as important as intelligence. In a study of emotion, learning and its effect on performance, Höpfl and Linstead (1997) investigated the learning process in children. They concluded that the learning process in children includes not just the content which is being taught, but also self-esteem, the appreciation of their own work, and how to communicate and relate with their mates and teachers. This means that effective learning and performance are functions of not only rational abilities but also emotional capabilities. Results of specific research on emotional intelligence and academic performance are unified and conclusive that emotional intelligence is associated with performance. Parker, Creques, Harris, Majeski, Wood and Hogan (2003) state that emotional competencies are crucial to excellent academic performance. Low and Nelson (2004) also propose that emotional intelligence competencies are crucial to the academic performance of students. A study of the correlation between emotional intelligence and academic performance amongst undergraduates, Maraichelvi and Ryan (2013) found a positive connection between emotional intelligence and academic performance. Studying medical students, Chew, Zain and Hassan (2013) found that emotionally intelligent students performed better in both tests and examinations. These findings are consistent with those of Nwadinigwe and Azuka-Obieke (2012); Ogundokun and Adeyemo (2010); Abdullahi (2009); Marquez, Martin, Bracket (2006) and Tella and Tella (2003).

\section{Methods and Data Analyses}

To explore the correlation between emotional intelligence and academic performance of final year undergraduates, the survey design is adopted. Data was gathered using questionnaires and a total number of two hundred (200) final year undergraduates (male and female) from the university's varying departments were randomly sampled. One hundred and fifty two (152) questionnaires were retrieved. The following competencies were employed as variables under emotional intelligence: intrapersonal relationship, interpersonal relationship, adaptability, stress management and general mood (Bar-.On, 1997). The variable for academic performance was the Cumulative Grade Point Average. The following hypotheses were tested:

$\mathrm{Ho1}_{0}$ Intrapersonal relationship has no significant effect on academic performance.

Ho2: Interpersonal relationship has no significant effect on academic performance.

Ho3: Adaptability has no significant relationship with academic performance.

H04: Stress management has no significant effect on academic performance.

H05: General Mood has no significant effect on academic performance.

The reliability test of the instrument was conducted using test re-test reliability approach which yielded $r=0.89$ and internal consistency was measured by Cronbach Alpha of 0.886 . See the distribution Table 1 .

Table 1: Distribution of respondents and response rate

\begin{tabular}{|l|c|c|}
\hline Respondents Departments & Questionnaire administered (sampled) & Total response \\
\hline Development Studies & 88 & $57 \%$ \\
\hline Science and Technology & 64 & $43 \%$ \\
\hline Total & 152 & 100.0 \\
\hline Gender/Category & Questionnaire administered (sampled) & Total response \\
\hline Male & 77 & $38.5 \%$ \\
\hline Female & 75 & $37.5 \%$ \\
\hline No of Returned & 152 & 76 \\
\hline No of Not Returned & 48 & 24 \\
\hline Total no of Questionnaires & 200 & 100 \\
\hline
\end{tabular}

Source: Field Survey, 2015. 


\section{Data Analysis and Hypothesis Testing}

Table 2: Descriptive statistics of Emotional intelligence

\begin{tabular}{|l|c|c|}
\hline Responses & \multirow{2}{*}{ Total (N) } & Mean \\
\cline { 1 - 1 } Emotional Intelligence & 152 & 3.73 \\
\hline Intra Personal Relationship & 152 & 3.61 \\
\hline Inter Personal Relationship & 152 & 3.52 \\
\hline Adaptability & 152 & 3.58 \\
\hline Stress Management & 152 & 3.84 \\
\hline General Mood & 152 & \\
\hline
\end{tabular}

Source: Field Survey, 2015.

Hypothesis 1: Intrapersonal relationship has no significant effect on academic performance (CGPA)

\begin{tabular}{|c|c|c|c|c|}
\hline Model & R & R Square & Adjusted R Square & Std. Error of the Estimate \\
\hline 1 & $.590(\mathrm{a})$ & .348 & .342 & .49223 \\
\hline
\end{tabular}

a. Predictors: (Constant), INTRAPERSONAL RELATIONSHIP

ANOVA (b)

\begin{tabular}{|cl|c|c|c|c|c|}
\hline Model & & Sum of Squares & $\mathrm{df}$ & Mean Square & $\mathrm{F}$ & Sig. \\
\hline 1 & Regression & 13.075 & 1 & 13.075 & 53.965 & $.000(\mathrm{a})$ \\
& Residual & 24.472 & 101 & .242 & & \\
\hline & Total & 37.547 & 102 & & & \\
\hline
\end{tabular}

a. Predictors: (Constant), Intrapersonal relationship

b. Dependent variable: Academic performance

The summary table above shows the degree to which the difference in intrapersonal relationship can be explicated by academic performance is $34.8 \%$, i.e. ( $R$ square $=0.348$ ). The ANOVA table indicates the Fcal 53.965 at 0.0001 significance level. Intrapersonal relationship significantly affects academic performance of university students.

Coefficients (a)

\begin{tabular}{|cl|c|c|c|c|c|}
\hline & \multicolumn{2}{|c|}{ Unstandardized Coefficients } & Standardized Coefficients & $\mathrm{T}$ & Sig. \\
\hline & & $\mathrm{B}$ & Std. Error & Beta & $\mathrm{B}$ & Std. Error \\
\hline 1 & (Constant) & 1.458 & .226 & & 6.452 & .000 \\
& Intrapersonal Relationship & .438 & .060 & .590 & 7.346 & .000 \\
\hline
\end{tabular}

a. Dependent variable: Academic performance

The coefficient table above states how intrapersonal relationship assists academic performance of university students. Mathematically, the model can be described as follows; $Y=a+b x$ where ' $y$ ' is increase in academic performance and ' $x$ ' is intrapersonal relationship, ' $a$ ' is a constant factor and ' $b$ ' is the value of coefficient. As seen above, academic performance $=1.458+0.438$ intrapersonal relationship. Hence, for every $100 \%$ variation in academic performance of university students, intrapersonal relationship contributed $43.8 \%$. The significance level below 0.01 implies a statistical confidence of above $99 \%$. This implies that intrapersonal relationship assists academic performance of university students. Thus, the decision would be to accept the alternate hypothesis $\left(\mathrm{H}_{1}\right)$.

Hypothesis 2: Interpersonal relationship has no significant effect on academic performance (CGPA).

Model Summary

\begin{tabular}{|c|c|c|c|c|}
\hline Model & $\mathrm{R}$ & $\mathrm{R}$ Square & Adjusted R Square & Std. Error of the Estimate \\
\hline 1 & $.728(\mathrm{a})$ & .530 & .526 & .57698 \\
\hline
\end{tabular}

a. Predictors: (Constant), Interpersonal relationship 
ANOVA (b)

\begin{tabular}{|cl|c|c|c|c|c|}
\hline Model & & Sum of Squares & $\mathrm{df}$ & Mean Square & $\mathrm{F}$ & Sig. \\
\hline 1 & Regression & 37.959 & 1 & 37.959 & 114.026 & $.000(\mathrm{a})$ \\
& Residual & 33.623 & 101 & .333 & & \\
& Total & 71.582 & 102 & & & \\
\hline
\end{tabular}

a. Predictors: (Constant), Interpersonal relationship

b. Dependent Variable: Academic performance

The summary table above shows the degree to which the difference in interpersonal relationship can be explicated by academic performance is 53\% i.e. $(\mathrm{R}$ square $=0.530$ ). The ANOVA table indicates the Fcal 114.026 at 0.0001 significance level. Interpersonal relationship significantly affects academic performance.

Coefficients (a)

\begin{tabular}{|c|c|c|c|c|c|}
\hline Model & Unstand & ed Coefficients & Standardized Coefficients & T & Sig. \\
\hline & B & Std. Error & Beta & B & Std. Error \\
\hline $\begin{array}{ll}1 & \text { (Constant) } \\
& \text { Interpersonal relationship }\end{array}$ & $\begin{array}{l}.910 \\
.740\end{array}$ & $\begin{array}{l}.268 \\
.069\end{array}$ & .728 & $\begin{array}{c}3.392 \\
10.678\end{array}$ & $\begin{array}{l}.001 \\
.000\end{array}$ \\
\hline
\end{tabular}

a. Dependent Variable: Academic performance

The coefficient table above expresses how interpersonal relationship assists academic performance of university students. Mathematically, the model can be described as follows; $Y=a+b x$ where ' $y$ ' is increase in academic performance and ' $x$ ' is interpersonal relationship, ' $a$ ' is a constant factor and ' $b$ ' is the value of coefficient. As seen above, academic performance $=0.910+0.740$ interpersonal relationship. Hence, for every $100 \%$ change in academic performance, interpersonal relationship contributed 74\%. The significance level below 0.01 implies a statistical confidence of above 99\%. This implies that interpersonal relationship assists academic performance of university students. Thus, the decision would be to accept the alternate hypothesis $\left(\mathrm{H}_{1}\right)$.

Hypothesis 3: Adaptability has no significant relationship with academic performance (CGPA).

Model summary

\begin{tabular}{|c|c|c|c|c|}
\hline Model & $\mathrm{R}$ & $\mathrm{R}$ Square & Adjusted R Square & Std. Error of the Estimate \\
\hline 1 & $.643(\mathrm{a})$ & .414 & .408 & .50507 \\
\hline
\end{tabular}

a. Predictors: (Constant), Adaptability

ANOVA (b)

\begin{tabular}{|cl|c|c|c|c|c|}
\hline Model & & Sum of Squares & $\mathrm{df}$ & Mean Square & $\mathrm{F}$ & Sig. \\
\hline 1 & Regression & 18.173 & 1 & 18.173 & 71.239 & $.000(\mathrm{a})$ \\
& Residual & 25.764 & 101 & .255 & & \\
& Total & 43.937 & 102 & & & \\
\hline
\end{tabular}

a. Predictors: (Constant), Adaptability

b. Dependent variable: Academic performance

The results from the model summary table above shows the degree to which the difference in adaptability can be explicated by academic performance is $41.4 \%$ i.e. (R square $=0.414)$. The ANOVA table shows the Fcal 71.239 at 0.0001 significance level. Adaptability significantly affects academic performance of students.

Coefficients (a)

\begin{tabular}{|cl|c|c|c|c|c|}
\hline \multicolumn{2}{|l|}{ Model } & \multicolumn{2}{|c|}{ Unstandardized Coefficients } & Standardized Coefficients & $\mathrm{t}$ & Sig. \\
\hline & & $\mathrm{B}$ & Std. Error & Beta & $\mathrm{B}$ & Std. Error \\
\hline \multirow{2}{*}{1} & (Constant) & 1.719 & .246 & & 6.991 & .000 \\
& ADAPATABILITY & .558 & .066 & .643 & 8.440 & .000 \\
\hline
\end{tabular}

a. Dependent variable: Adaptability

The coefficient table above expresses how adaptability assists academic performance of university students. Mathematically, the model can be described as follows; $Y=a+b x$ where ' $y$ ' is increase in academic performance and ' $x$ ' is 
adaptability, ' $a$ ' is a constant factor and ' $b$ ' is the value of coefficient. As seen above, academic performance $=1.719$ +0.558 adaptability. Hence, for every $100 \%$ change in academic performance, students' adaptability contributed $55.8 \%$. The significance level below 0.01 implies a statistical confidence of above 99\%. This implies that adaptability assists academic performance of university students. Thus, the decision would be to accept the alternate hypothesis $\left(\mathrm{H}_{1}\right)$.

Hypothesis 4: Stress management has no significant effect on academic performance (CGPA).

Model Summary

\begin{tabular}{|c|c|c|c|c|}
\hline Model & $\mathrm{R}$ & R Square & Adjusted R Square & Std. Error of the Estimate \\
\hline 1 & $.117(\mathrm{a})$ & .014 & .004 & .73914 \\
\hline
\end{tabular}

a. Predictors: (Constant), Stress management

ANOVA (b)

\begin{tabular}{|cl|c|c|c|c|c|}
\hline Model & & Sum of Squares & df & Mean Square & $\mathrm{F}$ & Sig. \\
\hline 1 & Regression & .765 & 1 & .765 & 1.399 & $.001(\mathrm{a})$ \\
& Residual & 55.180 & 101 & .546 & & \\
& Total & 55.944 & 102 & & & \\
\hline
\end{tabular}

a. Predictors: (Constant), Stress management

b. Dependent variable: Academic performance

The results from the model summary table above shows the degree to which the difference in stress management can be explicated by academic performance is $14 \%$ i.e. (R square $=0.14$ ). The ANOVA table shows the Fcal 1.399 at 0.0001 significance level. Stress management significantly affects the academic performance of students.

Coefficients (a)

\begin{tabular}{|cl|c|c|c|c|c|}
\hline \multicolumn{2}{|l|}{} & \multicolumn{2}{|c|}{ Unstandardized Coefficients } & Standardized Coefficients & T & Sig. \\
\hline & & $\mathrm{B}$ & Std. Error & Beta & B & Std. Error \\
\hline 1 & (Constant) & 3.432 & .348 & & 9.856 & .000 \\
& STRESSMANAGEMENT & .305 & .089 & .117 & 1.183 & .240 \\
\hline
\end{tabular}

a. Dependent variable: Academic performance

The coefficient table above expresses how stress management assists academic performance of university students. Mathematically, the model can be described as follows; $Y=a+b x$ where ' $y$ ' is increase in academic performance and ' $x$ ' is stress management, ' $a$ ' is a constant factor and ' $b$ ' is the value of coefficient. As seen above, academic performance $=$ $3.432+0.305$ stress management. Hence, for every $100 \%$ change in academic performance, stress management contributed $30.5 \%$. The significance level below 0.01 implies a statistical confidence of above $99 \%$. This implies that stress management assists academic performance of university students. Thus, the decision would be to accept the alternate hypothesis $\left(\mathrm{H}_{1}\right)$.

Hypothesis 5: General mood has no significant impact on academic performance (CGPA).

Table 4.4.2.1:

Model Summary

a. Predictors: (Constant), General mood

\begin{tabular}{|c|c|c|c|c|}
\hline Model & R & R Square & Adjusted R Square & Std. Error of the Estimate \\
\hline 1 & $.594(\mathrm{a})$ & .353 & .350 & .958 \\
\hline
\end{tabular}

Table 4.4.2.2: ANOVA (b)

\begin{tabular}{|cl|c|c|c|c|c|}
\hline Model & & Sum of Squares & $\mathrm{df}$ & Mean Square & $\mathrm{F}$ & Sig. \\
\hline \multirow{2}{*}{1} & Regression & 139.933 & 1 & 139.933 & 152.461 & $.000(\mathrm{a})$ \\
& Residual & 256.992 & 280 & .918 & & \\
& Total & 396.926 & 281 & & & \\
\hline
\end{tabular}

a. Predictors: (Constant), General mood

b. Dependent variable: Academic performance 
The results from the model summary table above shows the degree to which the difference in general mood can be explicated by academic performance is $35.3 \%$ i.e. ( $R$ square $=0.353$ ). The ANOVA table shows the Fcal 152.461at 0.000. General mood significantly affects academic performance of students.

Coefficients (a)

\begin{tabular}{|cl|c|c|c|c|c|}
\hline \multirow{2}{*}{ Model } & \multicolumn{2}{|c|}{ Unstandardized Coefficients } & Standardized Coefficients & $\mathrm{t}$ & Sig. \\
\cline { 3 - 7 } & $\mathrm{B}$ & Std. Error & Beta & $\mathrm{B}$ & Std. Error \\
& (Constant) & 1.537 & .190 & & 8.083 & .000 \\
& GENERALMOOD & .582 & .047 & .594 & 12.347 & .000 \\
\hline
\end{tabular}

a. Dependent variable: Academic performance

The coefficient table above expresses how stress management assists academic performance of university students. Mathematically, the model can be described as follows; $Y=a+b x$ where ' $y$ ' is increase in academic performance and ' $x$ ' is stress management, ' $a$ ' is a constant factor and ' $b$ ' is the value of coefficient. As seen above, academic performance = $3.432+0.305$ stress management. Hence, for every 100\% change in academic performance, stress management contributed $30.5 \%$. The significance level below 0.01 implies a statistical confidence of above $99 \%$. This implies that stress management assists academic performance of university students. Thus, the decision would be to accept the alternate hypothesis $\left(\mathrm{H}_{1}\right)$.

The coefficient table above expresses how general mood assists academic performance of university students. Mathematically, the model can be described as follows; $Y=a+b x$ where ' $y$ ' is increase in academic performance and ' $x$ ' is general mood, ' $a$ ' is a constant factor and ' $b$ ' is the value of coefficient. As seen above, academic performance $=1.537$ +0.582 general mood. Hence, for every $100 \%$ change in academic performance, general mood contributed $58.2 \%$. The significance level below 0.01 implies a statistical confidence of above 99\%. This implies that general mood assists academic performance of university students. Thus, the decision would be to accept the alternate hypothesis $\left(\mathrm{H}_{1}\right)$.

\section{Discussion of Findings}

The results of this research show a major connection between emotional intelligence and the academic performance of university undergraduates. This relationship is a predictor of performance. The findings are in consonance with the works of Abisamra (2000) and Bar-On (2003). Studies by Nigerian scholars, Ogundokun and Adeyemo (2010), Adeyemo (2007), Tella and Tella (2003), also have consistent findings with this study. The competencies of emotional intelligence are crucial to academic performance. Students who possess these competencies are at an advantage, as they have the ability to identify and regulate their own emotions and manage the emotions of others. The ability to utilize and rise above emotions is crucial to task accomplishment, whether in the academic setting or in the corporate world.

The term performance has become commonplace and liberally used, not only in the academia but also in the corporate world, where businesses compete in a volatile environment. The findings of this study indicate that performance is greatly influenced by the ability to manage emotions. This fact underpins the need for policy makers in the Nigerian higher education sector to re-evaluate university curricular and accommodate emotional intelligence as a subject, to enhance academic performance, so as to produce total graduates that can compete and exceed expectations in the workplace. In recent times, organizations are realizing that academic abilities are only part of the formula for success. These organizations are persuaded that the capacity to manage emotions advances performance (Oyewunmi, Oyewunmi, Ojo, Oludayo, 2015). The integration of emotional intelligence in university curricular will encourage performance, social interaction, physical and psychological wellbeing. Ogundokun and Adeyemo (2010) assert that, instituting suitable counseling initiatives and the provision of an enabling environment will also foster the integration of emotional intelligence in university curricular. Graduate business schools are also encouraged to design practical courses that will increase the emotional intelligence quotient of their students (Maraichelvi and Rayan, 2013). It is important to state the need for synergy between Nigerian universities and the corporate world. This will ensure that prospective employees meet the expectations of the increasingly dynamic corporate world. Another implication of this study is the need to review university admission tests and entry level tests in the workplace which are usually skewed towards testing cognitive abilities. This method of assessment should be re-focused to include emotional intelligence evaluations.

\section{Conclusion}

The role of policy formulation and implementation is fundamental within the context of this study; particularly as the 
incidences of policy inconsistencies have bedeviled several sectors in Nigeria. In specific terms, it is important for the primary regulatory authorities, in consonance with other stakeholders, to ensure that capacity building, infrastructural development and relative industrial peace is achieved and sustained. It should be noted that the socio-economic deficit in Nigeria, has restricted the opportunities for many graduates to be gainfully employed upon graduation. This situation makes it even more imperative for universities and tertiary institutions to prepare their products for the realities of the external environment.

\section{References}

Abdullahi, O. E. (2009). Introducing emotional intelligence in the Nigerian higher education. Journal of Educational Review, 2 (2), 97103.

Abisamra, N. (2000). The relationship between emotional intelligence and academic achievement of eleventh graders. Research in Education, FED 661.

Bar-On, R. (1997). Emotional quotient inventory: Technical manual. Toronto: Multi-Health Systems.

Chew, B. H., Zain, A., \& Hassan, F. (2013). Emotional intelligence and academic performance in first and final year medical students: A cross-sectional study. BMC Medical Education, 13(44).

Dulewicz, V., \& Higgs, M. J. (2000). ElQ-managerial user guide. Windsor: NFER-Nelson.

Gardner, H. (1983). Frames of mind: The theory of multiple intelligences. New York.

Gardner, H., \& Hatch, T. (1989). Multiple intelligences go to school: Educational implications of the theory of multiple intelligences. Educational Researcher, 18(8), 4-9.

Goleman, D. (1995). Emotional intelligence: Why it can matter more than IQ. Bloomsbury, London.

Goleman, D. (1996). Emotional intelligence. Bloomsbury, London.

Goleman, D. (1997). Beyond IQ: Developing the leadership competencies of emotional intelligence. London.

Höpfl, H., \& Linstead, S. (1997). Learning to feel and feeling to learn: Emotion and learning in organizations. Management Learning, 28(1), 5-12.

Kerr, R., Garvin, J., Heaton, N., \& Boyle, E. (2006). Emotional leadership effectiveness. Leadership and Organizational Development Journal, 27(4), 265-279.

Low, G. R., \& Nelson, D. A. (2004). Emotional intelligence: Effectively bridging the gap between high school and college. Texas Study Magazine for Secondary Education, Spring Edition.

McEnrue, M. P., \& Groves, K. (2006). Choosing among tests of emotional intelligence: What is the evidence? Human Resource Development Quarterly, 17(1), 9-42.

Marquez, P. G., Martin, R. P., \& Bracket, M. A. (2006). Relating emotional intelligence to social competence and academic achievement in high school students. Psichothema, 8(Supl.), 18-28.

Maraichelvi, A., \& Rayan, S. (2013). The relationship between emotional intelligence and academic performance among final year undergraduates. Universal Journal of Psychology, 1(2), 41-45.

Nigerian Economic Summit (2014). Retrieved: www.nigeriaeconomicsummit.org/nes-forward.html

Nwadinigwe, I. P., \& Azuka-Obieke, U. (2012). The impact of emotional intelligence on academic achievement of senior secondary school students in Lagos, Nigeria. Journal of Emerging Trends in Educational Research and Policy Studies, 3(4), 395-401.

Ogundokun, M. O., \& Adeyemo, O. A. (2010). Emotional intelligence and academic achievement: The moderating influence of age, intrinsic and extrinsic motivation. The African Symposium, 10(2), 127-141.

Oyewunmi, A. E., Oyewunmi, O. A., Ojo, I. S., \& Oludayo, O. A. (2015). Leaders' emotional intelligence and employees' performance: A case in Nigeria's public healthcare sector. International Journal of Human Resource Studies, 5(3), 23-37.

Parker, J. D. A., Creques, R., Harris, J., Majeski, S. A., Wood, L. M., \& Hogan. M. J. (2003). Academic success in high school: Does emotional intelligence Matter? ERIC Clearing House.

Salovey, P., \& Mayer, J. (1990). Emotional intelligence. Imagination, Cognition and Personality, 9, 185-211.

Sergio, R. P. (2001). Emotional intelligence and mental ability as determinants of job performance among plant supervisors in selected manufacturing firms. Unpublished Master's Thesis, De La Salle University, Behavioral Sciences Department, Philippines.

Steiner, C. (1997). Achieving emotional literacy. Bloomsbury Publishing, London.

Tella, A., \& Tella, A. (2003). Parental involvement, home background, and school environment as determinant of academic achievement of secondary school students in Osun State, Nigeria. African Journal of Cross-Cultural Psychology and Sport Facilitation, 5, (2), 42-48.

Wesley, Y. (2013). Emotional intelligence center relaunched. Yale Daily News. Retrieved from http://yaledailynews.com/blog/2013/ 10/08/emotional-intelligence-center-relaunched/

Woodruffe, C. (2001). Promotional Intelligence. People Management, 11, 26-29. 